\title{
EFFECT OF JAW GROWTH TYPE ON DENTOFACIAL ANGLE IN ANALYZING LATERAL TELERADIOGRAPHIC
} IMAGES

Article history:

Submitted 20 March 2019

Accepted 27 June 2019

\section{Igor Fomin', Sergey Dmitrienko 2*, Dmitry Domenyuk', Andrey Kondratyuk $k^{4}$, Anna Arutyunova ${ }^{5}$}

\author{
${ }^{1}$ Department of Orthopedic and General Dentistry at the First Sechenov \\ Moscow State Medical University, Moscow, Russia \\ ${ }^{2}$ Department of Dentistry, Pyatigorsk Medical-Pharmaceutical Institute \\ (Branch of Volgograd State Medical University, Pyatigorsk, Stavropol \\ Region, Russia \\ ${ }^{3}$ Department of general dentistry and child dentistry, Stavropol State \\ Medical University Stavropol, Russia \\ ${ }^{4}$ Department of Dentistry, Saint-Petersburg State Pediatric Medical \\ University, Saint-Petersburg, Russia \\ ${ }^{5}$ Department of Pediatric Dentistry, Orthodontics and Maxillofacial \\ Surgery, Kuban State Medical University, Krasnodar, Russia
}

*Corresponding Author: s.v.dmitrienko@pmedpharm.ru

Specific features of the dentofacial morphology have always attracted various specialists - morphologists, dentists, forensic physicians $[1,2,5,10,11,12]$. To date, lateral head teleradiographic images still offer a fairly accurate diagnostic basis for dentofacial pathologies, and are used in dental clinic for orthodontic and prosthetic treatment [3]. There are methods of computer diagnostics proposed, which allow cephalometric analysis of various images, such as teleradiographic images of lateral and direct projections, computer tomograms at different levels, allowing evaluation of various craniofacial structures as a whole, and dentofacial segments, in particular $[4,9]$. Most coordinate points and planes of teleradiographic imaging have been discussed in works by both national and foreign experts, while such works are used to diagnose pathologies and identify the effect of comprehensive treatment [6,7]. The emergence of new data concerning dentofacial features in view of the gnathic and dental indicators, will aim us at detecting a relationship between their parameters and the position of the skull planes, as well as reveals the relevance of the issue in question. Assessment of the facial area growth type attracts orthodontists, whose tasks include the treatment of occlusion anomalies and the prediction of treatment outcomes, as well as that of relapse [8]. When analyzing teleradiographic images, the major planes include the skull base plane, the orbital, spinal, occlusal, and mandibular planes, which extend horizontally (anterior-posterior direction). The known diagonal lines include lines $\mathrm{N}-\mathrm{Ba}$ and $\mathrm{N}-\mathrm{Go}$, which are meaningful in identifying the face growth type. However, we have found no marks that would allow us to separate the facial and the cranial parts of the head, and detect the relationship of this plane with other lines of the head, which served the aim of the study.

Aim of study:

to identify specific features of the dentofacial angle in people with different types of jaw growth.

\section{MATERIAL AND METHODS}

A cephalometric study was carried out involving 151 persons falling in the age group of $21-35$. To perform the teleradiographic image analysis, common points were marked: N (Nasion), C (Condylion), Ar (Articulare), T1, T2, Pg (Pogonion). We have proposed the facial area plane of the head or the cranialfacial line (CFL), which passed through the points $\mathrm{N}$ and $\mathrm{C}$, and separated the facial section of the head from the cranial one. The mandibular plane (ML) had a traditional structure and passed through the most convex points of the mandible lower body edge (points Gn and T2). The intersection of these lines shaped the dentofacial angle, which we used for the cephalometry analysis in people with different types of facial growth (horizontal, vertical and neutral). The type of face growth was determined based on the size of the mandibular angle, which was shaped by tangent lines to the lower edge of the body and the mandible ramus bones. The angle from $119^{\circ}$ to $123^{\circ}$ corresponded to a neutral type of jaw growth. A decrease and an increase in the angle pointed at the horizontal and vertical types of growth, respectively.

\section{RESULTS AND DISCUSSION}

The cephalometric analysis showed that in people with a neutral type of the facial area had the mandibular angle at $120.73 \pm 1.18^{\circ}$. At the same time, the dentofacial angle formed by the intersection of the craniofacial and mandibular planes was $43.51 \pm 2.87^{\circ}$. In people with a horizontal face growth, the mandibular angle was significantly smaller $(p \leq 0.05), 108.93 \pm 3.62^{\circ}$ in the 
group in general. Besides, a significant decrease in the dentofacial angle (down to $36.61 \pm 2.17^{\circ}$ ) was observed. The vertical type of face growth was associated to an increase in the angles in question up to $126.11 \pm 2.19^{\circ}$ and $51.24 \pm 1.22^{\circ}$, respectively.

\section{CONCLUSION}

The above suggests that there is an additional criterion proposed for identifying the type of the facial area growth, namely, the dentofacial angle. Identifying orientation points for constructing the angle poses no issue, so that may prove a good tool for orthodontists seeking to predict the treatment outcomes.

\section{REFERENCES}

1. Borodina V.A., Domenyuk D.A., VeISGEIM L.D., DMitrienKo S.V. Biometry of permanent occlusion dental arches - comparison algorithm for real and design indicators. Archiv EuroMedica, 2018; Vol. 8; 1: 25-26. https://doi.org/10.35630/2199$885 \mathrm{X} / 2018 / 8 / 1 / 25$

2. DMitrienko S.V., Domenyuk D.A., KochKonYan A.S., Karslieva A.G., DMitrienko D.S. Interrelation between sagittal and transversal sizes of maxillary dental arches. Archiv EuroMedica, 2014; Vol. 4; 2: 10-13.

3. DMitrienko S.V., Davydov B.N., V.V. ShKarin, DoMENYUK D.A. Algorithm for determining the size of artificial teeth by the morphometric parameters of the face in people with full adentia. Dentistry. 2018; 97(6): 57-60.

4. ShKarin V.V., Davydov B.N., Domenyuk D.A., DMitrienko S.V. Non-removable arch orthodontic appliances for treating children with congenital maxillofacial pathologies - efficiency evaluation. Archiv EuroMedica, 2018; Vol. 8; 1: 97-98. https://doi. org/10.35630/2199-885X/2018/8/1/97

5. Domenyuk D.A., ShKarin V.V., Porfiriadis M.P., DMitrienko D.S., DMitrienKo S.V. Algorithm for forecasting the shape and size of dent arches front part in case of their deformations and anomalies. Archiv EuroMedica, 2017; Vol. 7; 2: 105-110.

6. Domenyuk D.A., Vedeshina E G., Dmitrienko S.V. Mistakes in Pont (Linder-Hart) method used for diagnosing abnormal dental arches in transversal plane. Archiv EuroMedica, 2016; Vol. 6; 2: 23-26.

7. Domenyuk D.A., Lepilin A.V., Fomin I.V., DMITRIENKo S.V., BUDAYCHIEV G.M-A. Improving odontometric diagnostics at jaw stone model examination. Archiv EuroMedica, 2018; Vol. 8; 1:34-35. https://doi.org/10.35630/2199-885X/2018/8/1/34

8. Korobkeev A.A., Domenyuk D.A., ShKarin V.V., DMitrienko S.V. Types of facial heart depth in physiological occlusion. Medical news of North Caucasus. 2018. - Vol. 13. - № 4. - P. 627-630. (In Russ., English abstract). DOI - https://doi.org/10.14300/ mnnc.2018.13122
9. LePILIN A.V., FoMin I.V., DoMenYuK D.A., DMitrienko S.V. Diagnostic value of cephalometric parameters at graphic reproduction of tooth dental arches in primary teeth occlusion. Archiv EuroMedica, 2018; Vol. 8; 1:37-38. https://doi. org/10.35630/2199-885X/2018/8/1/37

10. ShKarin V., Domenyuk D., Lepilin A., Fomin I., DMITRIENKo S. Odontometric indices fluctuation in people with physiological occlusion. Archiv EuroMedica, 2018; Vol. 8; 1: 12-18.

11. Korobkeev A. A., Domenyuk D. A., ShKarin V. V., DMitrienko S. V., Mazharov V. N. Variability of odontometric indices in the aspect of sexual dimorphism. Medical News of North Caucasus. 2019;14(1.1):103-107. DOI - https://doi. org/10.14300/mnnc.2019.14062 (In Russ.)

12. Dmitrienko T.D., Domenyuk D.A., PorfyriaDIS M.P., ARUTYUNOVA A.G., KoNDRATYUK A.A., Subbotin R.S. Connection between clinical and radiological torque of medial incisors at physiological occlusion. Archiv EuroMedica, 2019; Vol. 9; 1:29-37. https://doi.org/10.35630/2199$885 \mathrm{X} / 2019 / 9 / 1 / 29$ 